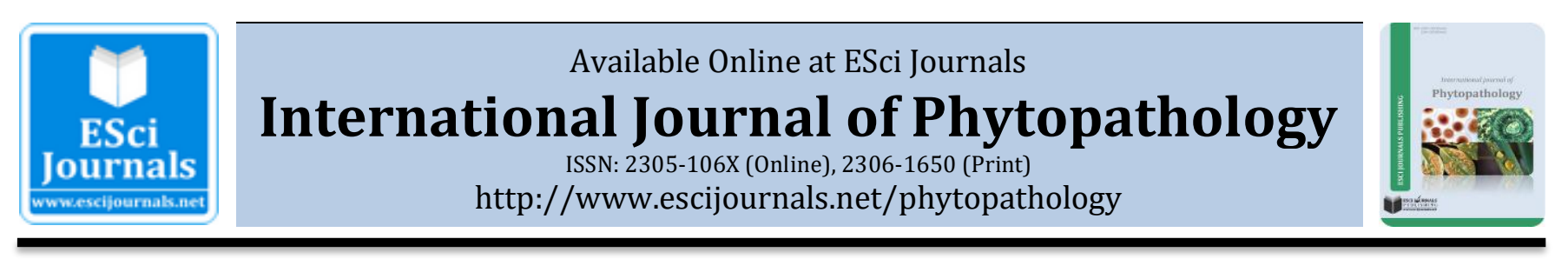

\title{
SCREENING FOR ANTAGONISTIC TROPICAL FUNGI AGAINST SELECTED MAIZE AND BEAN PATHOGENS
}

\author{
aKhadija N. Hassan, bJosphat.C. Matasyoh, cMarc Stadler \\ a Department of Biological Sciences, Egerton University, Nakuru, Kenya. \\ b Department of Chemistry, Egerton University, Nakuru, Kenya. \\ c Department of Microbial Drugs, Helmholtz Centre for Infection Research, Braunschweig, Germany.
}

\section{A B S T R A C T}

Phytopathogens are known to be the leading cause of important plant diseases which result in significant losses in agricultural crops. The need to maintain the level of yield both quantitatively and qualitatively is vital in order to curb the losses. So far there has been a positive advance recognized in research to the use of tropical fungi as biocontrol agents. The objective of this study was to screen for antagonistic tropical fungi against selected phytopathogens of maize (Zea mays L.) and beans (Phaseolus vulgaris L.) namely Fusarium graminearum, Fusarium moniliforme, Pythium ultimum, and Colletotrichum lindemuthianum in vitro. A total of 87 tropical fungi isolates were collected from Kakamega tropical rainforest, Kenya. Dual culture experiment was carried out to screen the tropical fungi against the selected phytopathogens. The bioassay was performed in a completely randomised design in triplicate and the inhibition zones recorded after every week for three weeks. Differential biocontrol ability among nine tropical fungi was noticed against F. moniliforme with the percentage inhibition increasing over time. Fusarium solani was the most active antagonist with an inhibition of $64 \%$ while Phaeomarasmius sp. had the lowest activity of $19.1 \%$ against $F$. moniliforme. Epicoccum sp. inhibited the mycelial growth of $P$. ultimum by $38 \%$ and also inhibited $C$. lindemuthianum by $58 \%$. None of the fungal antagonists inhibited the mycelial growth of F. graminearum. The outcome of this study indicates that tropical fungi can be used as biocontrol agents and can be further explored and developed into effective fungicides for management of phytopathogens.

Keywords: antagonist, bioassay, biocontrol, fungal phytopathogens, tropical fungi.

\section{INTRODUCTION}

Plant diseases, in particular pathogens, play a direct role in the destruction of natural resources in agriculture causing important losses, fungi being the most aggressive (Abou-Zeid et al., 2008; Yu et al., 2010). Maize and beans are not only staple foods but also a major source of dietary in most homes in Kenya due to their nutritional composition. Therefore these two crops are an important key determinant of food security for small holder farming communities. Disease outbreaks are key constrain to maize and beans production. For instance, yield losses of up to $90 \%$ as a result of maize lethal necrosis led to grain loss of 126,000 metric tons valued at $\$ 52$ million in Kenya in the year 2012 (Mahuku et al., 2015). There have been

* Corresponding Author:

Email: khanuel@gmail.com

(C) 2016 ESci Journals Publishing. All rights reserved. cases of crop losses like the recent aflatoxin production by Fusarium species in Kenya, 2004 (Nyikal et al., 2004; Azziz-Baumgartner, 2006). These emerging diseases are not only important at a global scale in terms of crop production but pose a high risk on a small scale especially small holder farmers.

Although, chemical compounds (fungicides) have shown promising results in controlling fungal diseases, phytotoxicity and fungicide residues are serious problems leading to environmental pollution and human health hazards (Patil et al., 2012). Their negative impact on the environment and their abuse in application which has favoured the development of pathogens resistant to fungicides has rendered them unattractive to farmers. In this context, the great task now facing scientists is to develop alternative, environmentally friendly disease management strategies such as biological control which 
has been proposed for several plant pathogens. Biological control of plant pathogens by use of natural antagonistic microorganisms has emerged as a promising alternative and realistic approach to reduce the use of chemical pesticides in agriculture.

Numerous microorganisms have been identified and play a considerable role in limiting the populations of phytopathogens. Trichoderma species have widely been studied and proven to be a potential antagonist against a variety of fungal phytopathogens (Schubert et al., 2008; Živković et al., 2010; Patil et al., 2012; Martínez-Medina et al., 2014). Tropical forest have a rich biodiversity of fungal communities (Rosa et al., 2011) and the magnitude of fungal diversity in tropical forests is unclear, and new species remain to be described (Hawksworth, 2004). Among the tropical fungi, endophytes have been studied and known to produce a wide range of secondary metabolites with biological activities (Huang et al., 2001; Chomcheon et al., 2006). Most of the tropical fungi belong to Ascomycota phylum and have been documented to have remarkable richness in antimicrobial activity (Arnold and Lutzoni 2007; Vaz et al., 2009; Vieira et al., 2011). The present study addressed the biocontrol efficacy and mechanisms of tropical fungi as biocontrol agents against selected phytopathogens of maize and beans.

\section{MATERIALS AND METHODS}

Collection and isolation of tropical fungi: A total of 87 tropical fungi were collected from Kakamega tropical rain forest located at $00^{\circ} 16^{\prime} \mathrm{N}, 34^{\circ} 53^{\prime} \mathrm{E}$, where both the primary and secondary forests exist with indigenous plant species acceptable by the neighboring communities as medicinal. Random sampling of the tropical fungi was done in September 2014 based on ethno botanical information obtained from the local community. Isolation was done immediately upon collection. The inner part of the basidiomycetes sample was picked with a fine sterile forceps and stuck onto the inner top side of a petri dish containing Potato Dextrose Agar (PDA) media amended with streptomycin sulphate $250 \mathrm{mg} / \mathrm{L}$ by the help of silicone high vacuum grease, where the spores were left to drop on the media plate overnight. Thereafter, a sterile spatula was used to cut out the stamp of spores and placed on a media plate. For the ascomycetes, the perithecia were cut open with a sterile scalpel to release spores, which were picked with a fine needle, and plated in sterilized Yeast Malt Glucose (YMG) media containing streptomycin sulphate $250 \mathrm{mg} / \mathrm{L}$ and incubated at $25^{\circ} \mathrm{C}$. The bacteria free isolates were then transferred to pure
YMG media at $\mathrm{pH}$ of 6.3, after which they were transferred to YMG media plates amended with ivermectin $50 \mathrm{mg} / \mathrm{L}$. The mite free isolates were finally plated on pure YMG media. For identification purposes the program BLAST (Basic Local Alignment Search Tool) was used to compare the consensus sequences of the isolates with published sequences of the "Genbank" (http://blast.ncbi.nlm.nih. gov/Blast.cgi). Within this tool published sequences of a database are compared to the consensus sequences generated out of the raw data. The tropical fugi isolates examined were considered authentic if the best hits of the BLAST search (depending on query coverage and max identity) were nearly related to the strain presumed or at least belonged to the same family.

Isolation of Plant Pathogens: Four phytopathogens; Fusarium graminearum, Fusarium moniliforme, Pythium ultimum, and Colletotrichum lindemuthianum, which cause ear rots, root rots and bean anthracnose, respectively were isolated from infected plant materials collected from Nakuru, Narok and Bomet counties. The infected plant materials were washed under running tap water to remove any soil and blotted dry. Small sections were cut and surface sterilized for 10 seconds with $2 \%$ sodium hypochlorite containing $0.1 \%$ Tween 20 . The plant tissues were rinsed three times each in two washes of sterile distilled water and blotted dry with sterile paper towels. Thereafter, they were plated on PDA and SDA plates amended with streptomycin sulphate 250 $\mathrm{mg} / \mathrm{L}$ to inhibit any bacterial growth (Whiteside, 1986). The plates were then incubated at $25^{\circ} \mathrm{C}$ for $4-7$ days and monitored for mycelial growth. The cultures obtained were sub-cultured to obtain pure and axenic cultures. Identification of the isolates on basis of symptomatological evidence was done at the Department of Biological Sciences of Egerton University. Identity of the Colletotrichum lindemuthianum was further confirmed through pathogenicity test on a bean plant both in green house and in the field.

Antimicrobial assays of the tropical fungi against the phytopathogens: All the tropical fungi were subjected to bioassay in vitro against each of the four phytopathogens using the dual culture method. Mycelia agar blocks were cut using a cork borer $(7 \mathrm{~mm}$ in diameter) from the actively growing tropical fungal cultures and inoculated opposite the phytopathogens approximately $4 \mathrm{~cm}$ apart on PDA media. The plates were incubated in a dark room with temperatures regulated at $25^{\circ} \mathrm{C}$ and monitored for growth inhibition. 

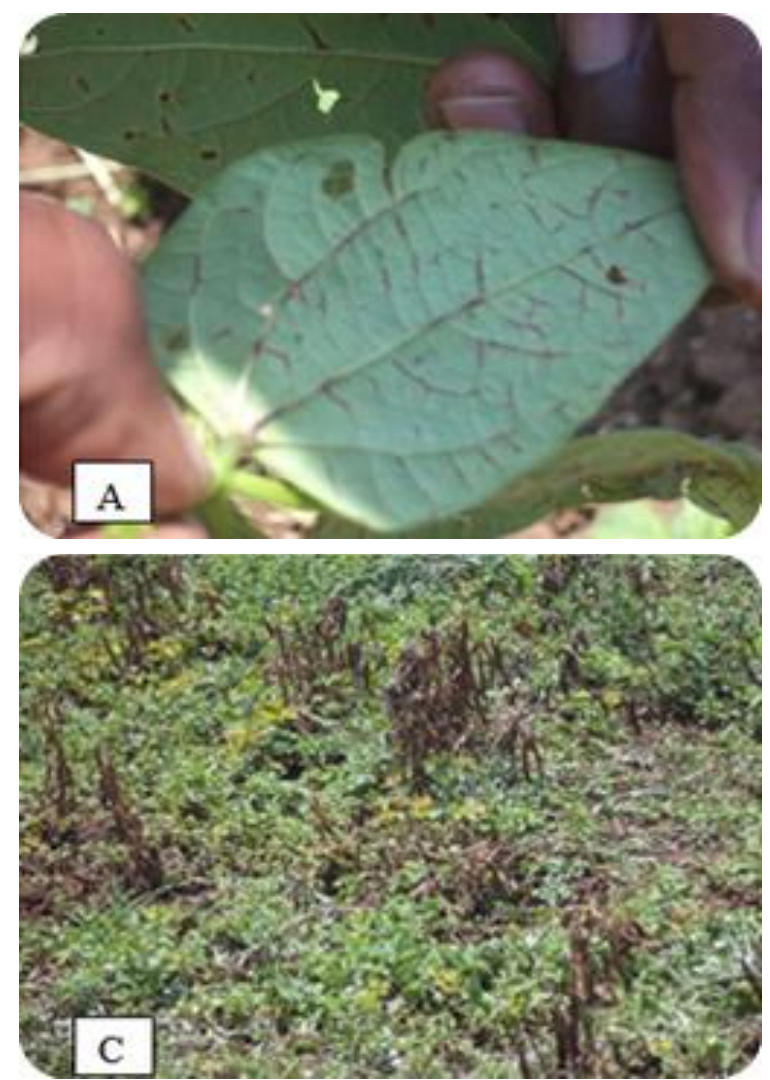
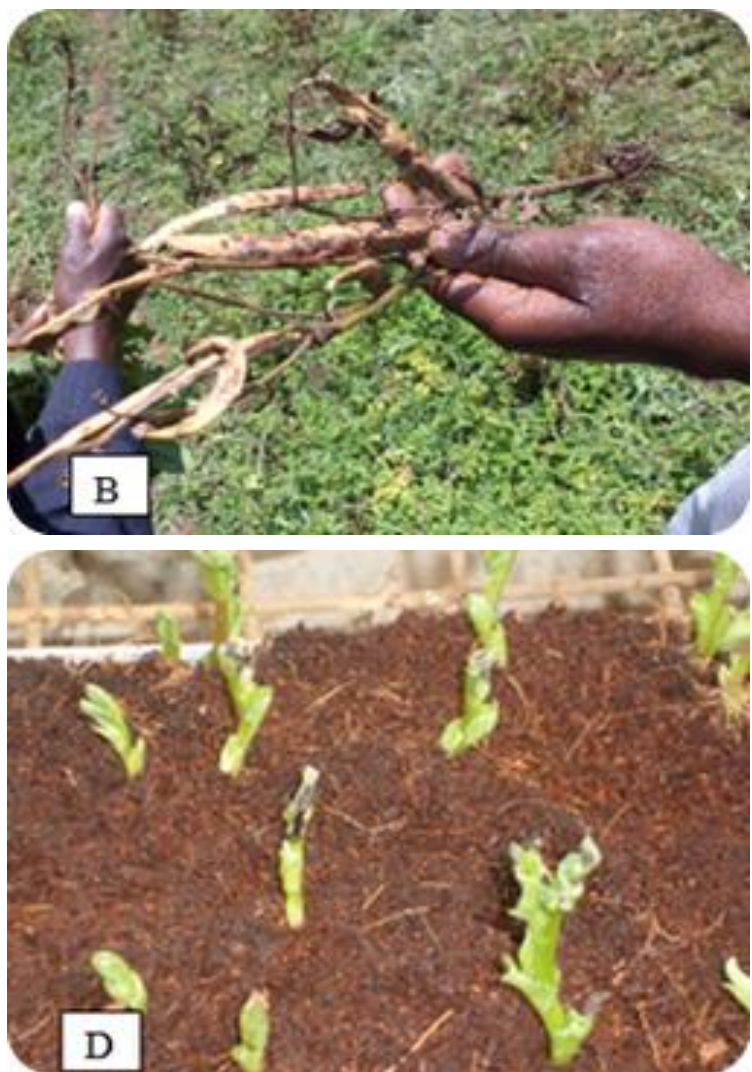

Figure 1. Symptoms of bean anthracnose manifesting itself on leaves (A), pods (B and C) and seedlings (D).

\section{RESULTS}

Antimicrobial activity of tropical fungi against the four phytopathogens: Nine different isolates of tropical fungi inhibited the mycelial growth of F. moniliforme (Table 1) while one isolate (Epicoccum sp.) inhibited the growth of $P$. ultimum and C. lindemuthianum. However, none of the tropical fungal isolates inhibited F. graminearum. After 10 days of incubation the Epicoccum sp. inhibited radial growth of $P$. ultimum and $C$. lindemuthianum by $14 \%$ and $63 \%$ respectively, and at 21 days the percentage inhibition for $P$. ultimum increased to $38 \%$ while for $C$. lindemuthianum it reduced to 58\%. Results showed that among the nine bioactive tropical fungal isolates,
Phaeomarasmius sp., and Epicoccum sp. proved to be the least potent bioagents against $F$. moniliforme while Fusarium solani and F.oxysporum were the most active. The percentage inhibition was generally seen to increase as the days progressed from 10 days to 21 days (Table 1). Six of the isolates inhibited more than $50 \%$ of the mycelial growth except for Phaeomarasmius sp., Epicoccum sp. and Pestalotiopsis sp. Differential biocontrol ability among the nine antagonists was noticed against $F$. moniliforme. Figures 2, 3 and 4 show different modes of action exhibited by the tropical fungi on the three phytopathogens; F. moniliforme, $P$. ultimum and $C$. lindemuthianum.

Table 1. Inhibition zones displayed by different tropical fungi against Fusarium moniliforme and their percentage inhibition.

\begin{tabular}{|c|c|c|c|}
\hline Tropical fungi / & Inhibition zone (mm) (Fusarium moniliforme) & \multicolumn{2}{|c|}{ Percent Inhibition (\%) } \\
\hline Treatment & & 10 days & 21 days \\
\hline Fusarium solani & $34.5 \pm 3.5^{\mathrm{ab}}$ & 63.3 & 64.0 \\
\hline Fusarium oxysporum & $32 \pm 4.4^{b c}$ & 54.2 & 61.9 \\
\hline Fusarium sp. & $30.5 \pm 5^{b c d}$ & 46.7 & 55.8 \\
\hline Fusarium sp. & $28.2 \pm 2.7 \mathrm{bcd}$ & 57.5 & 57.1 \\
\hline Pezizomycetes sp. & $23.8 \pm 2.5^{\mathrm{bcde}}$ & 46.7 & 59.2 \\
\hline Phomopsis sp. & $20.5 \pm 2.5^{\text {cdef }}$ & 37.5 & 53.1 \\
\hline Pestalotiopsis sp. & $20.5 \pm 2.5^{\text {cdef }}$ & 37.5 & 46.3 \\
\hline Epicoccum sp. & $14.83 \pm 2.15^{\mathrm{ef}}$ & 25.83 & 39.46 \\
\hline Phaeomarasmius sp. & $10 \pm 1.88^{f}$ & 26.67 & 19.05 \\
\hline Negative control & $44.50 \pm 2.01^{\mathrm{a}}$ & - & - \\
\hline
\end{tabular}

Means with same letter within a column are not significantly different according to Turkey's test. 
Inhibition zones between the test organisms and phytopathogens (C-T) were measured in a period of 7 21 days and the resulting percentage inhibition zones were determined as:

$$
L=\frac{(C-T)}{C} \times 100
$$

$\mathrm{L}=$ inhibition of radial mycelial/colony growth; $\mathrm{C}=$ radial growth measurement of pathogen in control; $\mathrm{T}=$ radial

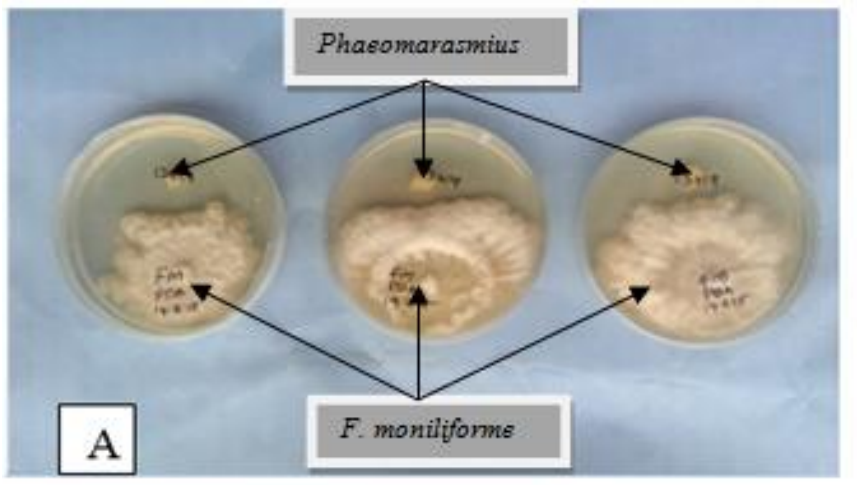

growth measurement of pathogen in the presence of antagonist (Hajieghrari et al., 2008).

The data collected on inhibition zones as a result of antagonistic tropical fungi were subjected to analysis of variance (ANOVA) using Statistical Analysis System (SAS Institute, 2001) software. Treatment means were separated using Turkey's HSD test whenever ANOVA showed significant treatment effects.

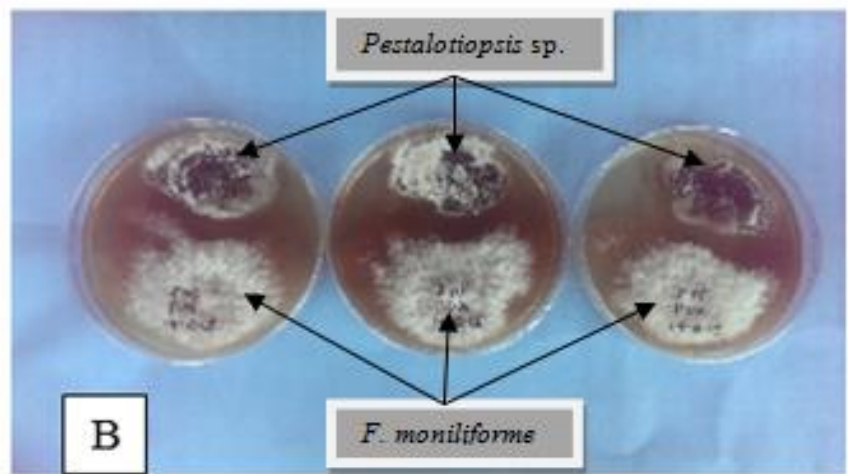

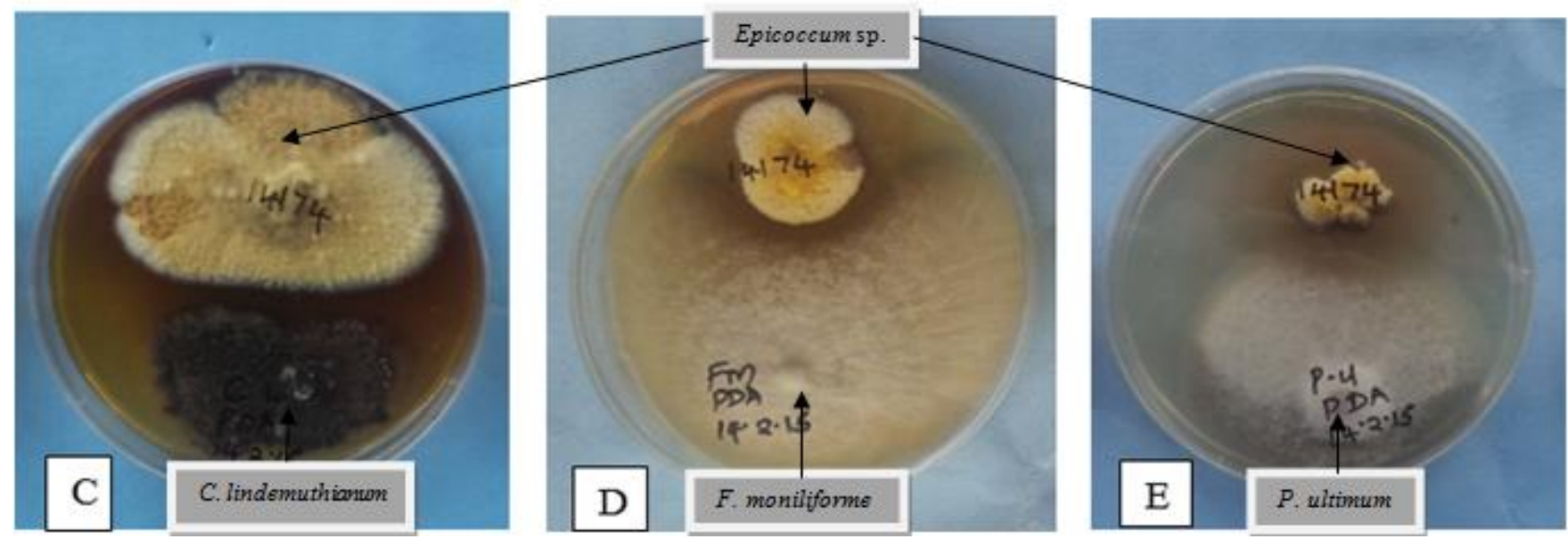

Figure 2. Different tropical fungi displaying antibiosis as a mechanism of inhibition against phytopathogens after 21 days. Activity of tropical fungal isolates Phaeomarasmius sp. (A), Pestalotiopsis sp. (B) and Epicoccum sp. (D) against $F$. moniliforme. Activity of Epicoccum sp. against C. lindemuthianum (C) and P. ultimum (E).
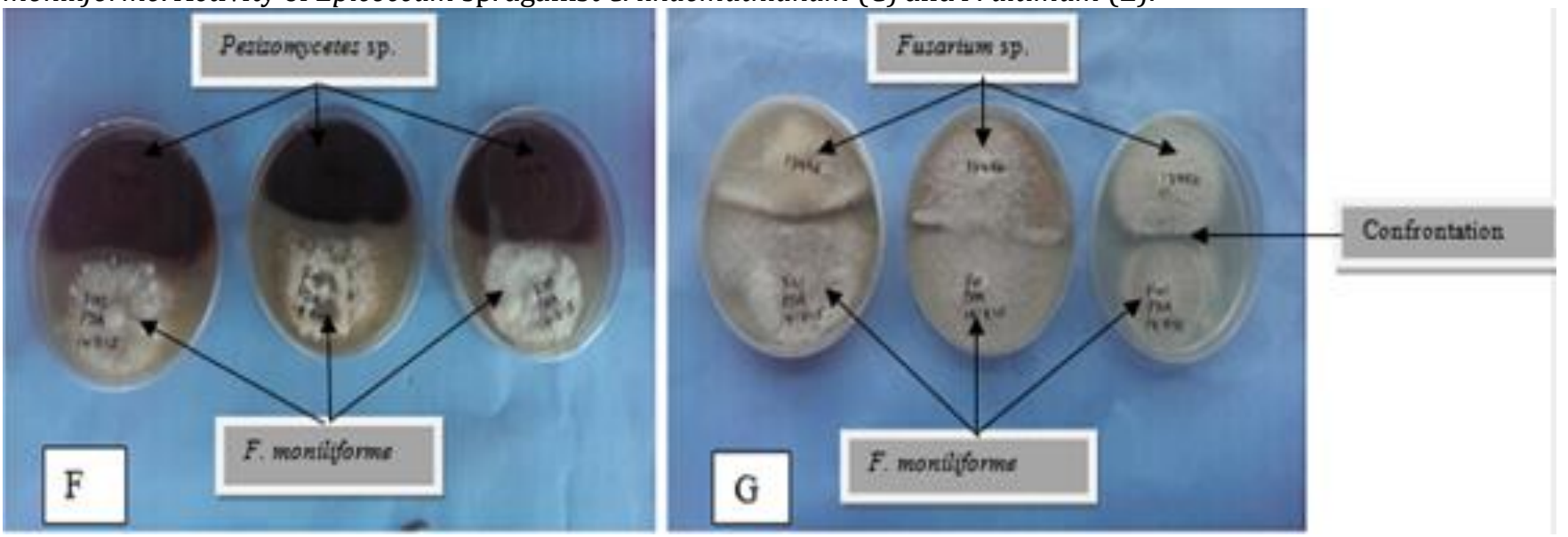

Figure 3(a). Dual antagonism demonstrated by different tropical fungi against Fusarium moniliforme after 21 days. 


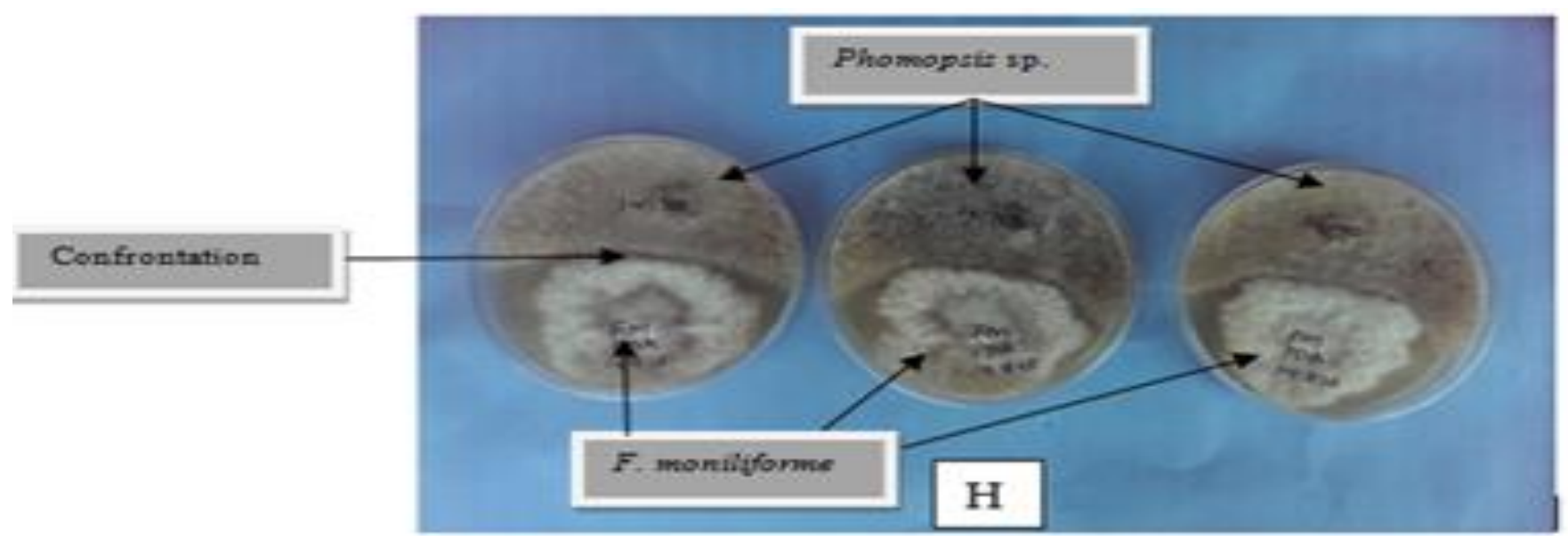

Figure 3. Dual antagonism demonstrated by different tropical fungi against Fusarium moniliforme after 21 days.

Both F. moniliforme and the tropical fungi isolate $(\mathrm{F}$ and G) were noted to be inhibiting each other while the tropical fungus seemed to be inhibited by the $F$. moniliforme $(\mathrm{H})$. Epicoccum sp. inhibited both the growth and sporulation of Pythium ultimum (Figure 4). This was also evident with isolate 14327 (Fusarium sp.).
The change of colour where both the tropical fungi isolate and pathogen almost meet could be attributed to lack of sporulation or production of chemical component responsible for inhibition. This was observed with Epicoccum sp. and Fusarium sp. as the antagonistic mechanism against $P$. ultimum.

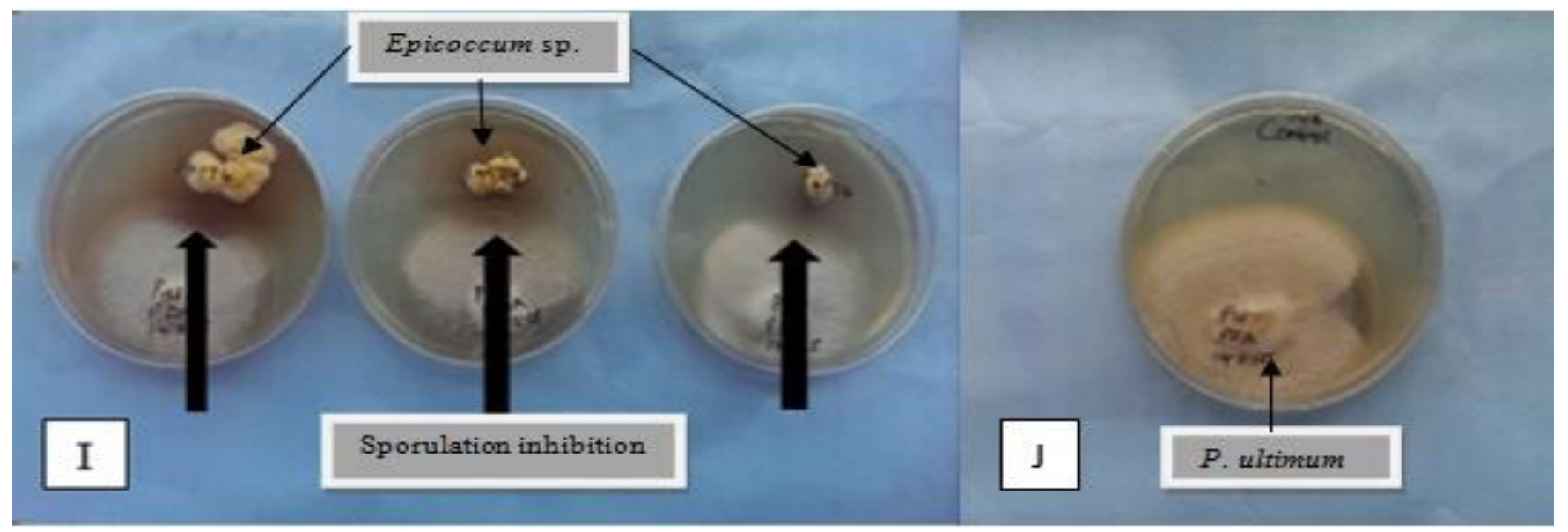

Figure 4. Tropical fungus 14174 (Epicoccum sp.) inhibiting sporulation of Pythium ultimum after 21 days.

Pythium ultimum (I) inhibited by Epicoccum sp. Pythium ultimum (J) not inhibited by any tropical fungi (negative control).

\section{DISCUSSION}

Antagonistic fungal isolates have been used as bio-agents to control plant pathogens. Rhizospheric, saprophytic and endophytic microorganisms are the most studied antagonists which have proven to be potent in controlling fungal plant pathogens (Schubert et al., 2008). Tropical fungi which include the above named types have been on the target by many researchers for the past decades due to their ability to control or suppress growth of phytopathogens especially soil-borne and post-harvest fungal plant pathogens (Verma et al., 2007; Fatima et al., 2009; Ara et al., 2012). Some of the active tropical fungal isolates identified in this study have been known to exist as endophytes. For instance, isolate 14174 which was identified as Epicoccum sp. was effective against $F$. moniliforme, $P$. ultimum and $C$. lindemuthianum. Epicoccum spp. especially E. nigrum has been known to be an endophyte which produces active metabolites (Wang et al., 2014). Use of epicoccolides as antibacterial and antifungal polyketides from Epicoccum sp. associated with Theobroma cacao has been shown to have antimicrobial activity against $P$. ultimum (Talontsi et al., 2013). Epicoccum sp., Pestalotiopsis sp. (isolate 14179) and Phomopsis sp. (isolate 14170) have also been associated with antimicrobial activity against target fungal organisms (Vieira et al., 2014). Pestalotiopsis sp. has recently been reported to produce a novel compound which is antibacterial and antiyeast (Subban et al., 2013). 
Other ascomycetes like Trichoderma, Xylaria and Fusarium species form the most frequent antagonistic fungi encountered (Bacon et al., 2001; Joseph and Priya 2011; Vieira 2011). From this current study, the named active tropical fungi isolates 14167, 14164, 13427 and 13427 were Fusarium sp. Isolate 13419 identified as Phaeomarasmius sp. a basidiomycete, had the lowest antifungal activity against $F$. moniliforme among the active tropical fungi isolates and has also been known to inhibit plant pathogens (Thomas et al., 2008). Several studies involving basidiomycetes in production of bioactive compounds against microbes have been carried out and they have been proved to be effective against microorganisms (Stadler and Hoffmeister, 2015). Mushroom fruiting bodies (basidiomes) seem to be particularly talented in producing unique terpenoids, and the molecular background behind the biosynthesis of some of those compounds has only recently been elucidated (Quin et al., 2014).

Three antagonistic mechanisms were displayed in this study of tropical fungi against phytopathogens. Antifungal enzymes production could have been the main mode of inhibition demonstrated by the tropical fungi isolates 14167, 14164, 14327, 14179, 14174 and 13419; identified as F. solani, F. oxysporum, Fusarium sp., Pestalotiopsis sp., Epicoccum sp. and Phaeomarasmius sp. respectively. The mechanism of antifungal antagonists could be due to the secretion of hydrolytic enzymes such as chitinase-b-3 glucanase, chitosanase, and proteases (Moreno- Perez et al., 2014) which degrade the fungal cell wall or the secretion of antifungal compounds (Khamna et al., 2009; Elamvazhuthi and Subramanian, 2013). Dual antagonism exhibited by Phomopsis sp., Fusarium sp. And Pezizomycetes sp was another observed mechanism of inhibition. There was a clear confrontation between the antagonist and the phytopathogen with no distinct inhibition zone. Competition for space and nutrients perhaps was the mode of action between the antagonists (Fusarium sp., Phomopsis sp. and Pezizomycete sp.) and F. moniliforme. Generally, either the combination of extracellular hydrolytic enzymes and secondary antifungal metabolite(s) or the secondary antifungal metabolite(s) alone can be assumed to play a major role in the inhibition of fungal growth (Prapagdee et al., 2008).

Inhibition of sporulation was shown by Epicoccum sp. (isolate 14174) against P. ultimum. A change in the mycelia colour was noticed where the antagonist was in close proximity with P. ultimum. Sporulation is a key component for several purposes because fungal spores are frequently used as propagules to infect plants (Rodrigues et al., 2010). Several studies have reported different biocontrol agents inhibiting sporulation of fungal pathogens both in vitro and in field trials as a mechanism of control against phytopathogens. For instance, sporulation of $F$. moniliforme was completely inhibited by three species of Trichoderma and one Penicllium sp. in vitro (Begum et al., 2015). Various isolates of Trichoderma spp. have been screened against F. oxysporum f. sp. Lycopersici by dual culture technique and noted to inhibit its sporulation (Sundaramoorthy and Balabaskar, 2013). Field studies have also reported success in managing fungal pathogens by inhibiting sporulation. In a farm in Panama, treatment with C. rosea reduced the incidence of Cacao pods with sporulating leisons of Monillophthora roreri by 10\% (Mejía et al., 2008). These examples support the potential of tropical fungi as biocontrol agents against pathogens.

\section{CONCLUSION}

Nine of the collected tropical fungi; Fusarium solani, F. oxysporum, two unidentified Fusarium spp., Pestalotiopsis sp., Epicoccum sp., Phaeomarasmius sp., Phomopsis sp. and Pezizomycetes sp., had antimicrobial activity against three fungal phytopathogens; Fusarium moniliforme, Colletotrichum lindemuthianum and Pythium ultimum indicating that the tropical fungi are potential antifungal agents that can be used to manage plant diseases.

\section{ACKNOWLEDGEMENTS}

The authors gratefully acknowledge the funding support granted by National Council of Science and Technology (NACOSTI) and Alexander von Humboldt Foundation. Many thanks and appreciation to the Helmholtz Centre for Infection Research, Braunschweig, Germany (MWIS) for their assistance in laboratory experiments.

\section{REFERENCES}

Abou-Zeid, A. M., Altalhi, A. D., and El-Fattah, A. 2008. Fungal control of pathogenic fungi isolated from some wild plants in Taif Governorate, Saudi Arabia. Malaysian Journal of Microbiology. 4: 3039.

Ara, I., Rizwana, H., Al-Othman, M. R. and Bakir, M. A. 2012. Studies of actinomycetes for biological control of Colletotrichum musae pathogen during post-harvest anthracnose of banana. African Journal of Microbiology Research. 6: 3879-3886. 
Arnold, E. A., and Lutzoni, F. 2007. Diversity and host range of foliar fungal endophytes: Are tropical leaves biodiversity hotspots? Ecology. 88: 541-549.

Azziz-Baumgartner, E., Kimberly, L., Gieseker, K., Heather Strosnider, H. H., Banziger, E. M., and Bhat, R.V. 2006.Workgroup Report: Public Health Strategies for Reducing Aflatoxin Exposure in Developing Countries. Environmental Health Perspective. 114:1898-1903.

Bacon, C. W., Yates, I. E., Hinton, D. M., and Meredith, F. 2001. Biological control of Fusarium moniliforme in maize. Environmental Health Perspectives. 109: Pp 325.

Begum, S., Devi, R. T. and Singh, N. I. 2015. Evaluation of fungicides, biocontrol agents and botanicals for management of damping-off in cabbage seedlings caused by Fursarium moniliforme sheld. Journal of Applied and Natural Science. 7:106-110.

Chomcheon, P., Sriubolmas, N., Wiyakrutta, S., Ngamrojanavanich, N., Chaichit, N., Mahidol, C. and Kittakoop, P. 2006. Cyclopentenones, scaffolds for organic syntheses produced by the endophytic fungus mitosporicdothideomycete sp. LRUB20. Journal of Natural Products. 69: 1351-1353.

Elamvazhuthi1, P. and Subramanian, M. 2013. Antagonistic Activity of Actinomycetes from Jeypore Paddy Soils against Selective Phytopathogenic Fungi. Journal of Modern Biotechnology. 2: 66-72.

Fatima, Z., Saleemi, M., Zia, M., Sultan, T., Aslam, M., Rehman, R. and Chaudhary, M. F. 2009. Antifungal activity of plant growth-promoting rhizobacteria isolates against Rhizoctonia solani in wheat. African Journal of Biotechnology. 8.

Hajieghrari, B., Torabi-Giglou, M., Mohammadi, M. R. and Davari, M. 2008. Biological potential of some Iranian Trichoderma isolates in control of soil borne plant pathogenic fungi. African Journal of Biotechnology. 7: 967-972.

Hawksworth, D. 2004. Fungal diversity and its implications for genetic resource collections. Studies in Mycology. 50: 9-18.

Huang, Y., Wang, J., Li, G., Zheng, Z., and Su, W. 2001. Antitumor and antifungal activities in endophytic fungi isolated from pharmaceutical plants. FEMS Immunology of Medical Microbiology. 31: 163-167.

Joseph, B. and Priya, M. R. 2011. Bioactive Compound from Endophytes and their Potential in
Pharmaceutical Effect: A Review. American Journal of Biochemistry and Molecular Biology. 1: 291-309.

Khamna, S., Yokota, A., Peberdy, J. F., and Lumyong, S. 2009. Antifungal activity of Streptomyces spp. isolated from rhizosphere of Thai medicinal plants. International Journal of Integrative Biology. 6: 143-7.

Mahuku, G., Lockhart, B.E., Wanjala, B., Jones, M.W., Kimunye, J.N., Stewart, L.R., Cassone, B.J., Sevgan, S., Nyasani, J.O., Kusia, E. and Kumar, P.L., 2015. Maize lethal necrosis (MLN), an emerging threat to maize-based food security in sub-Saharan Africa. Phytopathology. 105: 956-965.

Martínez-Medina, A., Alguacil, M. D. M., Pascual, J. A., and Van Wees, S. C. 2014. Phytohormone profiles induced by Trichoderma isolates correspond with their biocontrol and plant growth-promoting activity on melon plants. Journal of Chemical Ecology. 40: 804-815.

Mejía, L. C., Rojas, E. I., Maynard, Z., Van Bael, S., Arnold, A. E., Hebbar, P., Samuel, G. J., Robbins, N. and Herre, E. A. 2008. Endophytic fungi as biocontrol agents of Theobroma cacao pathogens. Biological Control. 46: 4-14.

Moreno- Perez, P., Gamboa-Angulo, M., Heredia, G., Canto- Canche, B., Rosado-Vallado, M., MedinaBaizabal, I. L. and Tapia- Tussell, R. 2014. Antagonistic properties of mycromycetes from sinkholes of the Yucatan Penisula against fungal phytopathogens. Revista Mexicana de micologia. 40: 27-36.

Nyikal, J., misore, A., Nzioka, C. and Njuguna, C. 2004. Outbreak of aflatoxin poisoning - Eastern and Central provinces, Kenya, January-July 2004. MMWR. Morbidity and Mortality Weekly Report. U.S. Government Printing Office. 2004. Retrieved March 16, 2014 from High Beam Research: http://www.highbeam.com/doc/1P3700077151.html

Patil, A., Laddha, A., Lunge, A., Paikrao, H. and Mahure, S. 2012. In vitro Antagonistic Properties of Selected Trichoderma Species against Tomato Root Rot Causing Pythium Species. International Journal of Science, Environment and Technology. 1: 302 - 315.

Prapagdee, B., Kuekulvong, C. and Mongkolsuk, S. 2008. Antifungal Potential of Extracellular Metabolites Produced by Streptomyces hygroscopicus against 
Phytopathogenic Fungi. International Journal of Biological Sciences. 4:330-337.

Quin, M. B., Flynn, C. M., and Schmidt-Dannert, C. 2014. Traversing the fungal terpenome. Natural Product Reports. 31: 1449-1473.

Rodrigues, T. T., Maffia, L. A., Dhingra, O. D., and Mizubuti, E. S. 2010. In vitro production of conidia of Alternaria solani. Tropical Plant Pathology. 35: 203-212.

Rosa, L. H., Vieira, M. L. A., Cota, B. B., Johann, S., Alves, T. M. A., Zani, C. L. and Rosa, C. A. 2011. Endophytic Fungi of Tropical Forests: A Promising Source of Bioactive Prototype Molecules for the Treatment of Neglected Diseases, Drug Development - A Case Study Based Insight into Modern Strategies, Dr. Chris Rundfeldt (Ed.) Retrieved on 23rd May, 2015. http://www.intechopen.com/books/drug.

Schubert, M., Fink, S., and Schwarze, F. W. 2008. In vitro screening of an antagonistic Trichoderma strain against wood decay fungi. Arboricultural Journal. 31: 227-248.

Stadler, M. and Hoffmeister, D. 2015. Fungal natural products - the mushroom perspective. Frontiers in Microbiology. 6: Pp 127.

Subban, K., Subramani, R., and Johnpaul, M. 2013. A novel antibacterial and antifungal phenolic compound from the endophytic fungus Pestalotiopsis mangiferae. Natural Product Research. 27: 1445-1449.

Sundaramoorthy, S. and Balabaskar, P. 2013. Biocontrol efficacy of Trichoderma spp. against wilt of tomato caused by Fusarium oxysporum f. sp. lycopersici. Journal of Applied Biology \& Biotechnology. 1: 36-40.

Talontsi, F. M., Dittrich, B., Schüffler, A., Sun, H., and Laatsch, H. 2013. Epicoccolides: Antimicrobial and antifungal polyketides from an endophytic fungus Epicoccum sp. associated with Theobroma cacao. European Journal of Organic Chemistry. 15: 3174-3180.

Thomas, S. E., Crozier, J., Aime, M. C., Evans, H. C. and Holmes, K. A. 2008. Molecular characterisation of fungal endophytic morphospecies associated with the indigenous forest tree, Theobroma gileri, in Ecuador. Mycological Research. 112: 852-860.

Vaz, A. B., Mota, R. C., Bomfim, M. R. Q., Vieira, M. L., Zani, C. L., Rosa, C. A., and Rosa, L. H. 2009. Antimicrobial activity of endophytic fungi associated with Orchidaceae in Brazil. Canadian Journal of Microbiology. 55: 1381-1391.

Verma, M., Brar, S. K., Tyagi, R. D., Surampalli, R. Y. and Valero, J. R. 2007. Antagonistic fungi, Trichoderma spp.: panoply of biological control. Biochemical Engineering Journal. 37: 1-20.

Vieira, M. L., Hughes, A. F., Gil, V. B., Vaz, A. B., Alves, T. M., Zani, C. L. and Rosa, L. H. 2011. Diversity and antimicrobial activities of the fungal endophyte community associated with the traditional Brazilian medicinal plant Solanum cernuum Vell. (Solanaceae). Canadian Journal of Microbiology. 58: 54-66.

Vieira, M. L., Johann, S., Hughes, F. M., Rosa, C. A., and Rosa, L. H. 2014. The diversity and antimicrobial activity of endophytic fungi associated with medicinal plant Baccharis trimera (Asteraceae) from the Brazilian savannah. Canadian Journal of Microbiology. 60: 847-856.

Wang, B., Yu, J., Zhu, D., Chang, Y. and Zhao, Q. 2014. Maize ZmRACK1 is involved in the Plant Response to Fungal Phytopathogens. International Journal of Molecular Sciences. 15: 9343-9359.

Whiteside, J. 0. 1986. Semi selective media for the isolation of Elsinoe fawcettii from citrus scab pustule. Plant Disease. 70: 204-206.

Yu, H., Zhang, L., Li, L., Zheng, C., Guo, L., Li, W. and Qin, L. 2010. Recent developments and future prospects of antimicrobial metabolites produced by endophytes. Microbiological Research. 165: 437449.

Živković, S., Stojanović, S., Ivanović, Ž.,Gavrilović, V., Popović, T., and Balaž, J. 2010. Screening of antagonistic activity of microorganisms against Colletotrichum acutatum and Colletotrichum gloeosporioides. Archives of Biological Sciences. 62: 611-623. 